International Journal of Biological Sciences

ISSN 1449-2288 www.biolsci.org 2008 4(1):1-7

Short Research Communication

CIvyspring International Publisher. All rights reserved

\title{
Transplantation of adult neural progenitor cells transfected with Vascular Endothelial Growth Factor rescues graited cells in the rat brain
}

\author{
Martin H. Maurer ${ }^{1,2}$, Christine Thomas ${ }^{1}$, Heinrich F. Bürgers' ${ }^{1}$, Wolfgang Kuschinsky ${ }^{1}$
}

1. Department of Physiology and Pathophysiology, University of Heidelberg, Heidelberg, Germany.

2. Present address: SYGNIS Bioscience, Im Neuenheimer Feld 515, 69120 Heidelberg, Germany.

Correspondence to: Dr. Martin H. Maurer, Dept. of Physiology and Pathophysiology, University of Heidelberg, Im Neuenheimer Feld 326, 69120 Heidelberg, Germany. Phone: +49-6221-54-4032; Fax: +49-6221-54-4561; Email: maurer@physiologie.uni-heidelberg.de

Received: 2007.10.19; Accepted: 2007.11.30; Published: 2007.12.03

Growth factors are currently evaluated as therapeutics in stroke and neurodegeneration. Besides direct neurotrophic effects, they promote proliferation, survival, and differentiation of both transplanted and endogenous neural precursor cells (NPCs). In the current study, we investigated whether NPCs expressing Vascular Endothelial Growth Factor VEGF-A165 are a useful vehicle for growth factor delivery after transplantation into the caudate putamen of the rat brain. We found an increased survival of adenovirally transfected NPCs after 11 days, but not after 24 hours or 4 days. Additional brain immunohistochemistry revealed increased expression of the endothelial cell marker PECAM-1 (CD31) after 24 hours, 4 day, and 11 days after transplantation. In conclusion, we show that the graft itself is a useful vehicle for growth factor delivery, promoting the survival of NPCs. Moreover, transplantation of VEGF-expressing NPCs supports angiogenesis in the brain, which may contribute to potential brain repair.

Key words: neural progenitor cell; neurosphere; transplantation; BrdU; Vascular Endothelial Growth Factor; VEGF.

\section{Introduction}

Hematopoietic and angiogenic growth factors are currently re-considered as therapeutical agents in a number of neurological diseases, mainly neurodegenerative disorders like Parkinson's Disease, amyotrophic lateral sclerosis (ALS), or cerebrovascular events such as stroke. The major advantage of these growth factors is their well-described pharmacological behavior and their clinical use over several years which ensure drug safety. Although their molecular mechanism of drug action in the brain is not clearly identified, they all relate to neuroplasticity and stem cell growth and differentiation. Among the growth factors with neuroregenerative potential are erythropoietin (EPO) [1], granulocyte-colony stimulating factor (G-CSF) [2], and the vascular endothelial growth factor (VEGF) [3].

Originally, VEGF was described as angiogenesis factor, since one of its biological roles is promoting angiogenesis by sprouting and branching of pre-existing blood vessels. Additionally, VEGF prevents neurodegeneration $[4,5]$ and promotes neurogenesis [3] in vitro and in vivo. Neuroprotection in animal models of Amyotrophic Lateral Sclerosis (ALS) [6-8] have nurtured the hope of a therapeutical use of VEGF.

The VEGF protein family is constituted of at least 7 members (VEGF-A to -E, and PIGF-1 and -2), of which the VEGF-A isoform is represented by several splice variants $[9,10]$. The VEGF isoforms bind to specific receptors, including VEGF-R1 (flt-1), VEGF-R2
(KDR, flk-2), VEGF-R3 (flt-4), Neuropilin-1, Neuropilin-2, and heparan-sulfate proteoglycans [9, 10]. The angiogenic signals are mediated by the tyrosine kinases linked to VEGF-R1 and VEGF-R2 [11-14], whereas only little is known about the neuroprotective and neuroregenerative signal transduction processes.

In recent years, the transplantation of neural stem or progenitor cells -whether of embryonic or adult origin- has been discussed as an alternative to the activation of endogenous stem cells residing in the brain (for review, see [15]). In most paradigms, either the stem/progenitor cells or the growth factor are injected into the brain tissue. Therefore, we investigated in the present study whether the graft itself is a useful vehicle for the growth factor VEGF. Whereas a number of studies have shown the effects of VEGF in the diseased brain, we focused in the present study on transplantation into the intact, non-diseased brain to exclude cellular signaling by other means than VEGF, e. g. inflammation.

\section{Material and Methods}

\section{Cell culture}

NPCs were isolated from the subventricular zone of 4-6 weeks old male Wistar rats as described $[3,16]$. Protocols are concordant with the policy on the use of animals, as endorsed by the National Institutes of Health, and fulfill the requirements of German law. Briefly, brains were washed in $50 \mathrm{~mL}$ ice-cold Dulbecco's Phosphate Buffered Saline (DPBS) 
supplemented with $4.5 \mathrm{~g} / \mathrm{L}$ glucose (DPBS/Glc). Subventricular zones from 6 animals were dissected, washed in $10 \mathrm{~mL}$ DPBS/Glc and centrifuged for $5 \mathrm{~min}$ at $1600 \times \mathrm{g}$ at $4{ }^{\circ} \mathrm{C}$. After removal of the supernatant, the tissue was homogenized with scissors and scalpels, resuspended in $20 \mathrm{~mL}$ DPBS/Glc, and centrifuged for $5 \mathrm{~min}$ at $1600 \mathrm{x} \mathrm{g}$ at $4{ }^{\circ} \mathrm{C}$. The pellet was resuspended in $10 \mathrm{~mL}$ of $0.01 \%(\mathrm{w} / \mathrm{v})$ papain, $0.1 \%(\mathrm{w} / \mathrm{v})$ dispase II (neutral protease), $0.01 \%(\mathrm{w} / \mathrm{v})$ DNase I, $12.4 \mathrm{mM}$ $\mathrm{MgSO}_{4}$ in Hank's Balanced Salt Solution (HBSS), triturated well by a plastic pipette tip, and incubated at room temperature for $40 \mathrm{~min}$. In three washing steps, the homogenate was centrifuged for $5 \mathrm{~min}$ at $1600 \times \mathrm{g}$ a $4{ }^{\circ} \mathrm{C}$ and the pellet was resuspended in $10 \mathrm{~mL}$ Dulbecco's Modified Eagle's Medium (DMEM)-Ham's F12 medium supplemented with 100 units/mL penicillin, 100 units $/ \mathrm{mL}$ streptomycin, and $2 \mathrm{mM}$ L-glutamine. Cells were resuspended in $1 \mathrm{~mL}$ neurobasal-B27 medium and the cell number was counted. Cells were plated in $2 \mathrm{~mL}$ dishes at 200,000 cells in B27-neurobasal medium supplemented with 100 units/mL penicillin, 100 units/mL streptomycin, $20 \mathrm{ng} / \mathrm{mL}$ EGF, $20 \mathrm{ng} / \mathrm{mL}$ FGF-2, and $2 \mu \mathrm{g} / \mathrm{mL}$ heparin. A total of $4 / 5$ of the medium was replaced weekly, and cells were passaged every 2-2.5 weeks. The neural stem cells were maintained for 6-10 weeks in $5 \% \mathrm{CO}_{2}$ at $37^{\circ} \mathrm{C}$.

\section{Immunocytochemistry for marker proteins in neurospheres before transplantation}

The following primary antibodies directed against marker proteins for precursor cells have been used: for NPC markers, nestin (1:100; BD Pharmingen, Heidelberg, Germany), doublecortin (1:100; Chemicon, Temecula, CA, USA); for neuronal markers, tubulin BIII, clone TuJ-1 (1:100; Abcam, Cambridge, UK) and neurofilament 70 kDa NF70 (1:200; Chemicon); for astrocytes, glial acidic fibrillary protein GFAP (1:500; BD Pharmingen); for oligodendrocytes, O4 (1:100; Neuromics, Edina, MN, USA); and endothelial cells/capillaries CD31 (1:100; BD Pharmingen).

Neurospheres were grown adhesively on poly-L-lysin covered slides, fixed in $4 \%$ paraformaldehyde in PBST, pH 7.4 for $10 \mathrm{~min}$ and washed three times in PBST for 5 min each. Then the slides were blocked for $30 \mathrm{~min}$ in Seablock solution (Pierce, Rockford, IL, USA) and washed three times in PBST for $5 \mathrm{~min}$ each. The respective primary antibody was applied overnight at $4{ }^{\circ} \mathrm{C}$ in a humidified chamber. The next day, the slides were washed 3 times for $5 \mathrm{~min}$ in PBST. For double staining, the second primary antibody was applied. Then the sections were incubated with the respective FITC- or TRITC-conjugated secondary antibody (1:200, Jackson ImmunoResearch, West Grove, PA, USA) for $3 \mathrm{~h}$ at room temperature. After washing 3 times for $5 \mathrm{~min}$ each with PBST, nuclei were stained with 4',6-diamidino-2-phenylindole (DAPI, 1:5,000, Molecular Probes, Eugene, OR, USA) for $5 \mathrm{~min}$. Slides were embedded in fluoprotective mounting media [17] and stored at $4{ }^{\circ} \mathrm{C}$ in the dark until fluorescence microscopy.

\section{Labeling and adenoviral transfection of neural progenitor cells before transplantation}

For pulse labeling of the neural stem cells before transplantation, the thymidine analogue 5'-bromo-2-deoxy-uridine (BrdU; BrdU Labeling and Detection Kit I, Roche Diagnostics, Mannheim, Germany) was added to the cell culture medium daily in a final concentration $1 \mu \mathrm{mol} / \mathrm{L}$ for $48 \mathrm{~h}$. This allowed tracking of the grafted cells after transplantation.

Neural stem cells were transfected using the adenoviral vector AdPAC-VEGF as described previously [18]. Briefly, the vector containing the VEGF-A $\mathrm{A}_{165}$ gene was added to a single cell suspension of neural stem cells at a final concentration of $1.2 * 10^{8}$ viral particles and incubated for 4 days. The VEGF concentration in the cell culture medium was determined using an ELISA kit according to the manufacturer's instructions (BioSource International, Camarillo, CA, USA). The transfection efficiency in the cell culture was determined by cell counting as described elsewhere in detail [16]. Briefly, after sampling of a small drop of cell culture media containing neurospheres and freezing on a slide under a cover slip for $20 \mathrm{~min}$ at $80^{\circ} \mathrm{C}$, the immunostaining protocol for BrdU followed according to the same methodology described below for tissue sections.

\section{Transplantation of neural progenitor cells}

For transplantation, we used a modified protocol published previously [19]. Cells were trypsinized at 37 ${ }^{\circ} \mathrm{C}$ for $2 \mathrm{~min}$ and mechanically dissociated to a single cell suspension. The transplant consisted of 1,000,000 cells ( $5 \mu \mathrm{L}$ total volume) and was injected into the caudate putamen at AP $+0.5 \mathrm{~mm}, \mathrm{~L} \pm 2.5 \mathrm{~mm}$, DV -6.0 $\mathrm{mm}$ using a stereotactic apparatus (David Kopf Instruments, Tujunga, CA, USA). Four animals each were attributed to the experimental and control groups. The rats were decapitated after $24 \mathrm{~h}, 4 \mathrm{~d}$, and $11 \mathrm{~d}$, respectively. After removal of the skin and muscular tissue, the skull was opened by a circular incision. The brain was removed using a fine spatula and immersed in $-80{ }^{\circ} \mathrm{C}$ cold isopentane. Due to its high coefficient of heat conductance, isopentane allows fast and complete freezing of large tissue samples. The tissue was stored at $-80{ }^{\circ} \mathrm{C}$ until used. Frontal or sagittal cryosections, respectively, of $20 \mu \mathrm{m}$ were cut. The relative position of the section in the brain was determined using the stereotactic atlas of Paxinos and Watson [20].

\section{Immunohistochemistry for BrdU after transplantation}

The sections were fixed in $-20{ }^{\circ} \mathrm{C}$ methanol containing $1 \%(\mathrm{v} / \mathrm{v}) \mathrm{H}_{2} \mathrm{O}_{2}$ for $20 \mathrm{~min}$. Then the slides were washed once in bidestilled water for $5 \mathrm{~min}$, and twice in PBST for 5 min each. For DNA denaturation, the sections were treated in $2 \mathrm{~N} \mathrm{HCl}$ for $30 \mathrm{~min}$ at $37^{\circ} \mathrm{C}$ in a prewarmed water bath. For neutralization, the slides were washed twice for $5 \mathrm{~min}$ each in $0.1 \mathrm{M}$ sodium borate buffer, $\mathrm{pH} 8.5$. Then the sections were washed in PBST twice for 5 min each. After blocking of 
unspecific epitopes with SeaBlock (Pierce, Rockford, IL, USA) for $30 \mathrm{~min}$, the primary anti-BrdU antibody (1:50 in PBST; clone BU1/75 (ICR1), Accurate Chemical and Scientific Co., Westbury, NY, USA) was applied overnight at $4{ }^{\circ} \mathrm{C}$. The next day, sections were washed 3 times in PBST for $5 \mathrm{~min}$ each, and the FITC-labelled secondary antibody (Dianova, Hamburg, Germany) was applied for $2 \mathrm{~h}$ at room temperature. After washing tree times in PBST, slides were embedded in fluoprotective mounting media [17] and stored at $4{ }^{\circ} \mathrm{C}$ in the dark until fluorescence microscopy.

\section{Immunohistochemistry for CD31 after transplantation}

The rat brain sections were fixed in $4 \%$ paraformaldehyde in PBST, $\mathrm{pH} 7.4$ for $10 \mathrm{~min}$ and washed three times in PBST for 5 min each. Then the slides were blocked for 30 min in Seablock solution (Pierce, Rockford, IL, USA) and washed three times in PBST for $5 \mathrm{~min}$ each. The primary anti-CD31 antibody (1:50; BD Biosciences, Heidelberg, Germany) for detecting endothelial cells/capillaries was applied overnight at $4{ }^{\circ} \mathrm{C}$ in a humidified chamber. The next day, the slides were washed 3 times for 5 min in PBST. For double staining, the second primary antibody was applied. Then the sections were incubated with the TRITC-conjugated secondary antibody (1:200, Jackson ImmunoResearch, West Grove, PA, USA) for $3 \mathrm{~h}$ at room temperature. After washing 3 times for $5 \mathrm{~min}$ each with PBST, nuclei were stained with 4',6-diamidino-2-phenylindole (DAPI, 1:5,000, Molecular Probes, Eugene, OR, USA) for 5 min. Slides were embedded in fluoprotective mounting media [17] and stored at $4{ }^{\circ} \mathrm{C}$ in the dark until fluorescence microscopy.

\section{Image analysis}

Using the MCID Elite software, version 7.0 (ImagingResearch, St. Cathrines, Ontario, Canada), and a digital camera (CoolSnap cf, Roper Scientific, Tucson, AZ, USA; DAGE 300, MTI, Michigan City, IN, USA) we took automated tiled field images on a fluorescent microscope (DM-LR, Leica Microsystems, Bensheim, Germany). To estimate the total number of stained cells, the optical disector method was applied according to [21]. This unbiased stereological method is based on systematically counting of labeled cells with optical dissectors in a uniform sample which constitutes a known fraction of the volume of the region to be analyzed. Unbiased stereological methods do not require any assumptions with regard to the shape of the objects. Thus all objects, e. g. cells, in a given tissue section are sampled with the equal probability regardless of their shape or position.

The number of immunopositive cells in the brain sections was estimated using the optical disector technique. The disector frames had dimensions of 20 $\mu \mathrm{m} \times 20 \mu \mathrm{m}$. These frames were spaced in $20 \mu \mathrm{m}$ distance. Disector frames were sampled randomly throughout the regions of interest. Targets were counted within or when touching the inclusion borders of the optical disector frame. Using the stereology study mode of the MCID Elite software, version 7.0 (ImagingResearch, St. Cathrines, Ontario, Canada), we estimated the number of cells in the region of interest.

For cytometry and cell differentiation staining, images were recorded using semi-automated system equipped with a digital camera (PixelFly QE, PCO, Kehlheim, Germany) mounted on a fluorescent microscope (Zeiss Axiovert 200M, Zeiss, Göttingen, Germany). Standardized automatic acquisition was performed by AQuest software (TissueGnostics, Vienna, Austria) controlling filters, exposure, camera, and motor stage (Märzhäuser, Wetzlar, Germany). For image cytometry, all images were processed in the TissueQuest software (TissueGnostics, Vienna, Austria). Nuclei were detected by dissection algorithms in the DAPI channel. Then, immunopositive cells were detected by a non-annular signal grow algorithm around the nuclei. The signals for the respective primary antibody were plotted against the nuclear DAPI signals to create FACS-like scattergrams [16].

\section{Statistical analysis}

Results were compared by one-factorial ANalysis Of VAriance (ANOVA) with Bonferroni's correction for multiple testing using the SPSS 9.01 statistical software package (SPSS, Chicago, IL, USA). A P-value $<0.05$ was considered statistically significant.

\section{Results and Discussion}

Viral transfection with VEGF increases the survival of neural stem cells after transplantation

VEGF has been described as neuroprotective factor in vitro [3, 22] and in vivo [23]. In most studies, VEGF was added to the cell culture medium (e. g. in [3, 24]) or its local concentration in the brain was increased by injection or transfection (e. g. in [18]) and increased the survival and differentiation of cells transplanted into the central nervous system. A major problem of these studies was the delivery of VEGF, since preincubation of the graft or intracerebral transfection increases the local cerebral VEGF concentration only temporarily. A combination of grafting cells into the brain and transfecting the cells with VEGF may be a suitable solution.

A prerequisite of any transplantation study is to characterize the graft previous to the transplantation. Therefore, we characterized the cultured NPCs by immunostaining for multiple cellular markers (Fig. 1). Whereas the NPC markers Nestin and Doublecortin as well as the neuronal markers Tubulin-BIII and neurofilament $70 \mathrm{kDa}$ NF70 are expressed in the graft, only faint immunoreactivity is found for astrocytic (GFAP) and oligodendrocytic (O4) markers, and no immunoreactivity for endothelial cells/capillaries (CD31). 

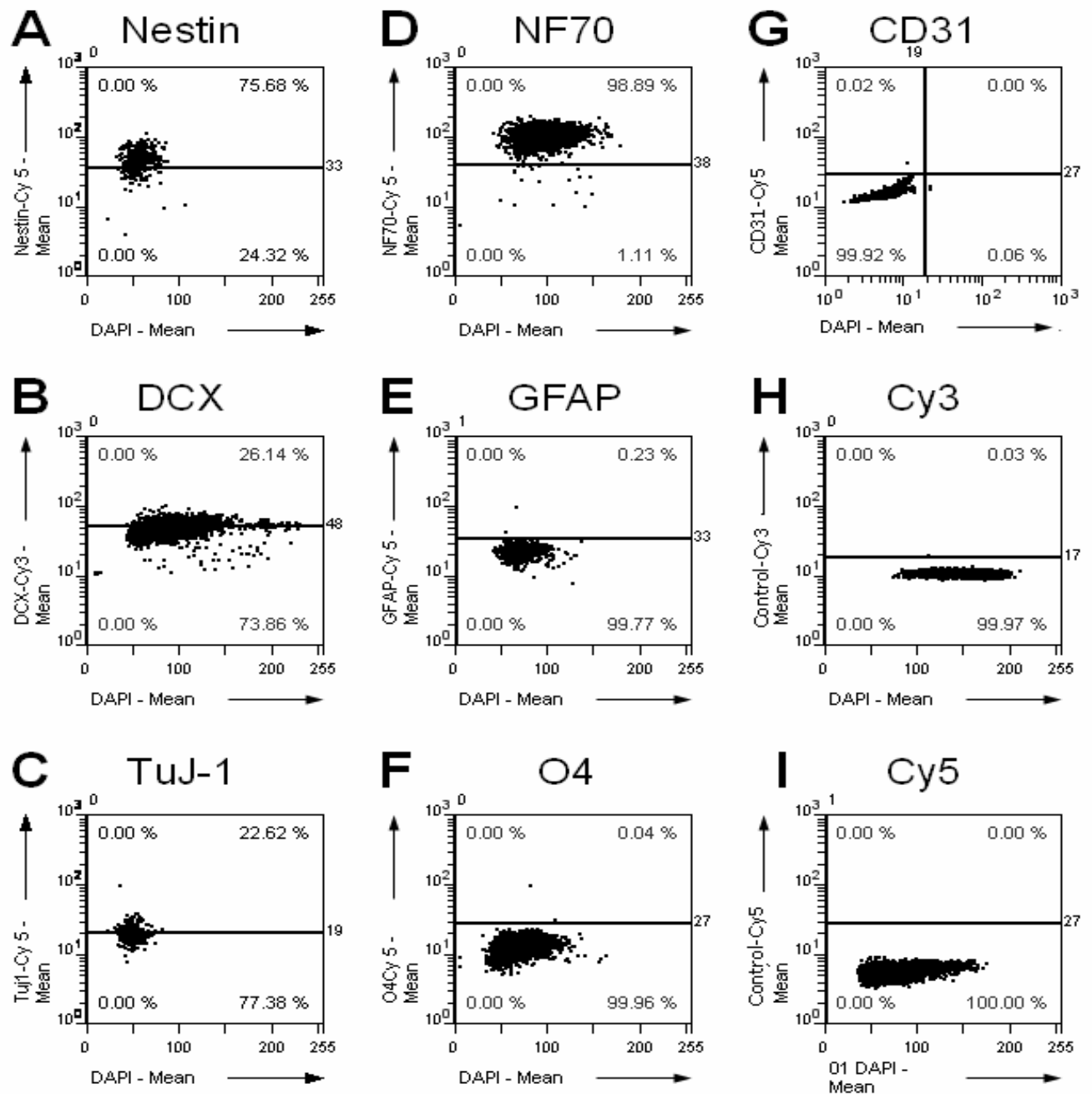

Fig. 1. Immunohistochemical characterization of the cultured NPCs. We stained the cultured cells using a set of different antibodies directed against marker proteins for precursor cells (A, nestin; B, doublecortin DCX), neurons (C, tubulin BIII, clone TuJ-1; D, neurofilament $70 \mathrm{kDa}$ NF70), astrocytes (E, glial acidic fibrillary protein GFAP), oligodendrocytes (F, O4), and endothelial cells/capillaries (G, CD31). Additionally, the respective controls for the secondary fluorescent antibodies labeled with Cy3 (H) and Cy5 (I) are shown. The percentage in the upper right corner of each panel gives the percentage of cells positive for the respective marker. The NPCs are highly positive for progenitor cell markers and neuronal markers, but they do only show faint immunoreactivity for astrocytic and oligodendrocytic markers, and no immunoreactivity for CD31 as well as for the negative controls.

In the present study, we investigated whether the transfection of NPCs with VEGF could increase the number of surviving neurons in the transplants. We introduced the VEGF-A $\mathrm{A}_{165}$ gene into NPCs by adenoviral vectors. NPCs showed a low basal expression of VEGF which was secreted into the cell culture medium at a concentration of about $12.1 \pm 12.2$ $\mathrm{pg} / \mathrm{mL}(\mathrm{N}=12$ biological replicates). After adenoviral transfection, the medium concentration of VEGF strongly increased to $243.1 \pm 37.2 \mathrm{pg} / \mathrm{mL}(\mathrm{N}=12$ biological replicates; $\mathrm{P}<0.05$ ) (Fig. 2) as soon as $24 \mathrm{~h}$ after transfection and was stable for at least 6 weeks (data not shown). The transfection efficiency was measured by cell counting and revealed $20-30 \%$ of transfected cells. Thus the secreted concentration of
VEGF per cell may be even higher.

We then grafted VEGF-transfected and non-transfected NPCs into the intact, non-diseased rat brain and measured cellular survival $24 \mathrm{~h}, 4 \mathrm{~d}$, and 11 $\mathrm{d}$ after transplantation by cell counting in a stereological paradigm. Whereas we did not see differences in the survival rates of transfected versus non-transfected cells after $24 \mathrm{~h}$ or $4 \mathrm{~d}$, VEGF labeling resulted in a doubling of the number of surviving cells $11 \mathrm{~d}$ after the transplantation $(\mathrm{N}=4$ animals in each group; $\mathrm{P}<0.05$ ) (Fig. 3).

In a previous study, the effects of the alternative splice form VEGF - $\mathrm{A}_{121}$ on the survival of transfected and grafted embryonic stem cells (day E14) were investigated in a rat model of brain ischemia [25]. The 
authors found that pretreatment with VEGF- $\mathrm{A}_{121}$ increased the survival of the transplanted cells and ameliorated sensorimotor behavior of the diseased animals. In the non-diseased brain, a stimulus promoting the survival of neural stem and progenitor cells may be absent. The cells then become apoptotic, unless factors of the local microenvironment prevent cell death. Under physiological conditions, there is a low basal expression of VEGF in the brain, which is dramatically increased under pathophysiological stimuli such as hypoxia [26, 27]. In the present study, we show that the local concentration of VEGF was increased in the brain microenvironment after the transplantation of VEGF-transfected cells. In an autocrine mode of action [28], VEGF overexpression then resulted in an increased survival of the NPCs.

\section{Transplantation of VEGF-transfected NPCs increases the number of CD31-positive cells in the brain}

Besides its neuroprotective effects, VEGF is originally known for its role in angiogenesis [4, 29]. Therefore, we were interested to which extend the VEGF-transfected, transplanted cells may contribute to the increase in angiogenic cells. The Platelet
Endothelial Cell Adhesion Molecule-1 protein (PECAM-1, CD31) is considered as marker protein for endothelial cells [30]. In the present study, we stained rat brain sections after transplantation of VEGF-transfected NPCs for the expression of PECAM-1. We found higher numbers of PECAM-1-positive cells after $24 \mathrm{~h}, 4 \mathrm{~d}$, and $11 \mathrm{~d}$ in the brains with VEGF-transfected transplants as compared to grafts containing the empty vector $(\mathrm{P}<0.05 ; \mathrm{N}=4)$ (Fig. 4). Although the absolute number of PECAM-1-positive cells decreased over time, transfection with VEGF produced relatively more PECAM-1-positive cells.

In general, transplanted cells seem to integrate or produce vessel-like structures in the brain. This is in accordance with other transplantation studies [31, 32], where increased survival of transplanted cells and endothelial differentiation have been described. Currently, it is unclear to which extend transplanted neural stem or progenitor cells attract the growth of blood vessels, or if they are able to differentiate into blood vessels [33, 34]. In the theory of the neurovascular niche, both hypotheses are supported in the literature, as well as in the present study.
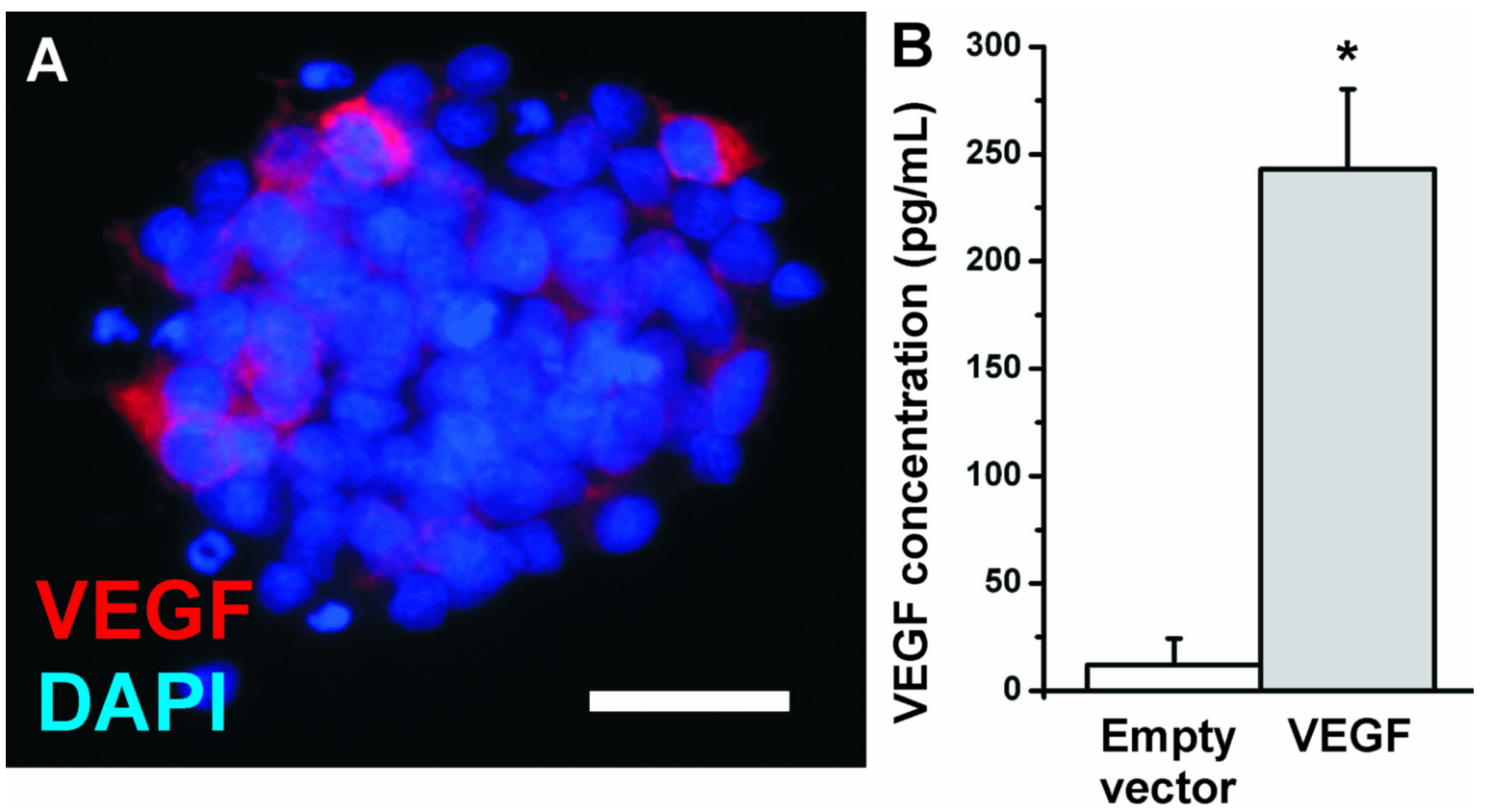

Fig. 2. VEGF expression in NPCs. (A) Immunostaining for VEGF (red). The antibody detects the VEGF-A165 isoform. Nuclei are counterstained with DAPI. (Scale bar, $25 \mu \mathrm{m}$ ). (B) VEGF expression in NPCs measured by ELISA. Whereas neural stem cells secrete about $20 \mathrm{pg} / \mathrm{mL}$ VEGF into the cell culture medium, adenoviral transfection with VEGF resulted in a more than 20-fold increase in the medium concentration. 


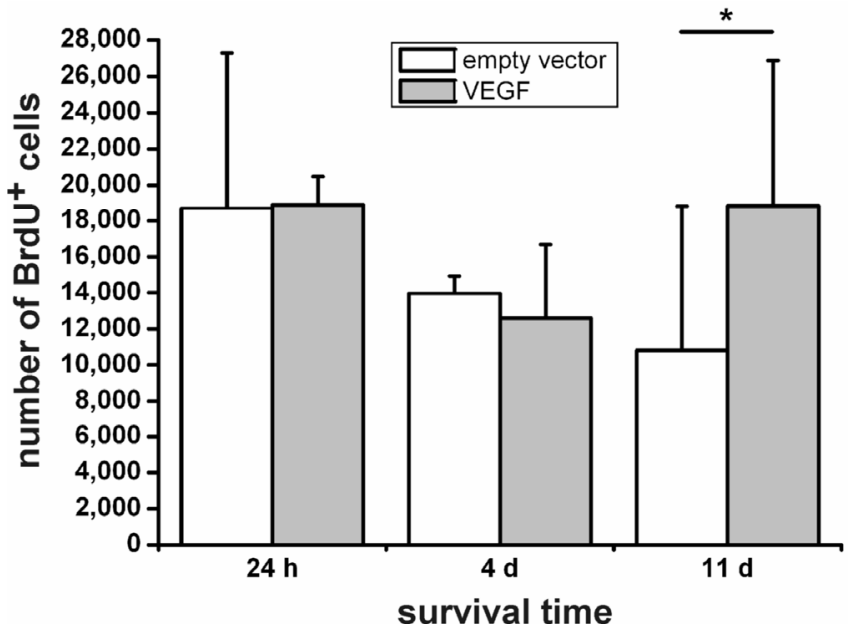

Fig. 3. Survival of transplanted neural stem cells. One day and 4 days after the transplantation, no differences can be seen between the VEGF-transfected and control (empty vector) NPCs. Only after 11 days, an increase of about 1.8 -fold in cell numbers in the sections can be found $(*, P<0.05)$. VEGF rescues transplanted neural stem cells.

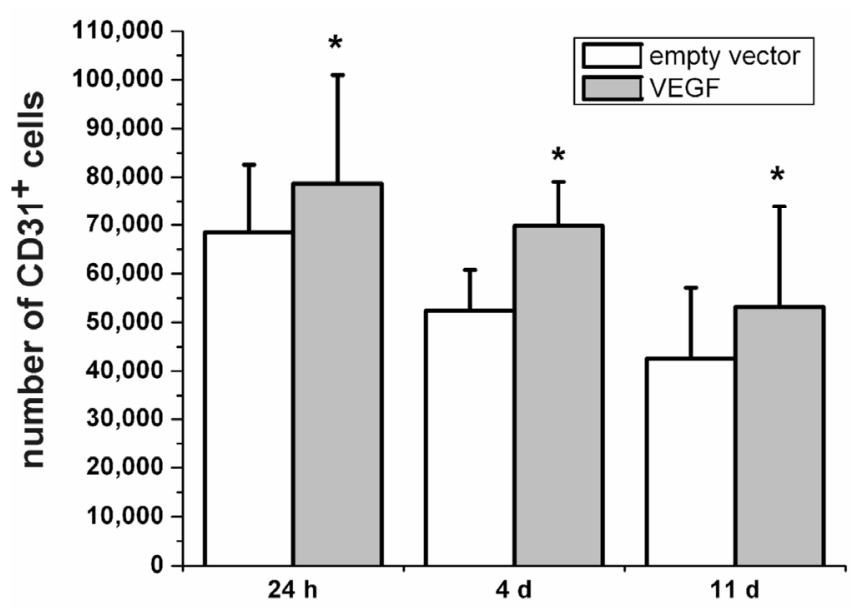

Fig. 4. Expression of the endothelial cell marker PECAM-1 (CD31). Higher numbers of CD31-positive cells can be seen for animals transplanted with VEGF-containing vectors compared to the transplantation of cells containing the empty control vectors for $24 \mathrm{~h}, 4 \mathrm{~d}$, and $11 \mathrm{~d}$ after the transplantation ( $^{*} \mathrm{P}<$ $0.05)$. In accordance with the survival analysis, the number of CD31-positive cells decreases over time in both groups.

\section{Conclusions}

Whereas the number of grafted adult neural progenitor cells decreases rapidly after transplantation into intact, non-diseased brain tissue, stimulation with VEGF-A $_{165}$ rescues transplanted NPCs from cell death. Thus grafting of VEGF-transfected cells may bring additional value to the survival of transplants as compared to non-transfected cells. Moreover, transplantation of VEGF-transfected cells increases the number of PECAM-1-positive cells in the brain, indicating increased angiogenesis in the target regions.

\section{Abbreviations}

BrdU: 5'-bromo-2-deoxy-uridine; NPC: Neural precursor cell; PECAM-1: Platelet Endothelial Cell Adhesion Molecule-1; VEGF: Vascular Endothelial Growth Factor.

\section{Conflict of Interest} exists.

The authors declared that no conflict of interest

\section{Acknowledgements}

We thank Mrs. Tilly Lorenz and Mrs. Maria Harlacher for technical assistance. This work was supported by the German Ministry of Education and Research (BMBF) within the National Genome Research Network NGFN-2 (01GS0496, to MHM and WK), the German Research Foundation (DFG, MA 2492/2-2, to MHM and WK) and the Estate of Friedrich Fischer (to MHM).

\section{References}

1. Shingo T, Sorokan ST, Shimazaki T, et al. Erythropoietin regulates the in vitro and in vivo production of neuronal progenitors by mammalian forebrain neural stem cells. J Neurosci. 2001; 21: 9733-43.

2. Schneider A, Krüger C, Steigleder T, et al. The hematopoietic factor G-CSF is a neuronal ligand that counteracts programmed cell death and drives neurogenesis. J Clin Invest. 2005; 115: 2083-98.

3. Maurer MH, Tripps WKC, Feldmann RE, et al. Expression of Vascular Endothelial Growth Factor and its receptors in rat neural stem cells. Neurosci. Lett. 2003; 344: 165-8.

4. Rosenstein JM and Krum JM. New roles for VEGF in nervous tissue--beyond blood vessels. Exp Neurol. 2004; 187: 246-53.

5. Storkebaum E and Carmeliet P. VEGF: a critical player in neurodegeneration. J Clin Invest. 2004; 113: 14-8.

6. Azzouz M, Hottinger A, Paterna JC, et al. Increased motoneuron survival and improved neuromuscular function in transgenic ALS mice after intraspinal injection of an adeno-associated virus encoding Bcl-2. Human molecular genetics. 2000; 9: 803-11.

7. Storkebaum E, Lambrechts D, Dewerchin M, et al. Treatment of motoneuron degeneration by intracerebroventricular delivery of VEGF in a rat model of ALS. Nat Neurosci. 2005; 8: 85-92.

8. Wang Y, Mao XO, Xie L, et al. Vascular endothelial growth factor overexpression delays neurodegeneration and prolongs survival in amyotrophic lateral sclerosis mice. J Neurosci. 2007; 27: 304-7.

9. Neufeld G, Cohen T, Gengrinovitch S, et al. Vascular endothelial growth factor (VEGF) and its receptors. Faseb J. 1999; 13: 9-22.

10. Robinson CJ and Stringer SE. The splice variants of vascular endothelial growth factor (VEGF) and their receptors. J. Cell Sci. 2001; 114: 853-65.

11. McMahon G. VEGF receptor signaling in tumor angiogenesis. Oncologist. 2000; 5: 3-10.

12. Zachary I. Vascular endothelial growth factor: how it transmits its signal. Exp Nephrol. 1998; 6: 480-7.

13. Zachary I. Signaling mechanisms mediating vascular protective actions of vascular endothelial growth factor. Am J Physiol Cell Physiol. 2001; 280: C1375-86.

14. Ortega N, Hutchings $\mathrm{H}$ and Plouet J. Signal relays in the VEGF system. Front Biosci. 1999; 4: D141-52.

15. Lindvall $\mathrm{O}$ and Kokaia Z. Stem cells for the treatment of neurological disorders. Nature. 2006; 441: 1094-6.

16. Maurer MH, Brömme JO, Feldmann RE, et al. Glycogen Synthase Kinase 3beta (GSK3beta) Regulates Differentiation and Proliferation in Neural Stem Cells from the Rat Subventricular 
Zone. Journal of proteome research. 2007; 6: 1198-208.

17. Osborn $\mathrm{M}$ and Weber $\mathrm{K}$. Immunofluorescence and immunocytochemical procedures with affinity purified antibodies: tubulin containing structures. Methods Cell Biol. 1982; 24: 97-132.

18. Vogel J, Hörner C, Haller C, et al. Heterologous expression of human VEGF165 in rat brain: dose-dependent, heterogeneous effects on $\mathrm{CBF}$ in relation to vascular density and cross-sectional area. J Cereb Blood Flow Metab. 2003; 23: 423-31.

19. Vescovi AL, Parati EA, Gritti A, et al. Isolation and cloning of multipotential stem cells from the embryonic human CNS and establishment of transplantable human neural stem cell lines by epigenetic stimulation. Exp Neurol. 1999; 156: 71-83.

20. Paxinos $G$ and Watson $C$. The rat brain in stereotactic coordinates. Sydney, New York, London: Academic Press; 1982.

21. Mouton PR. Principles and Practices of Unbiased Stereology: An Introduction for Bioscientists. Baltimore: Johns Hopkins University Press; 2002.

22. Jin KL, Mao XO and Greenberg DA. Vascular endothelial growth factor: direct neuroprotective effect in in vitro ischemia. Proc Natl Acad Sci (USA). 2000; 97: 10242-7.

23. Jin $\mathrm{K}$, Zhu Y, Sun $Y$, et al. Vascular endothelial growth factor (VEGF) stimulates neurogenesis in vitro and in vivo. Proc Natl Acad Sci (USA). 2002; 99: 11946-50.

24. Mani N, Khaibullina A, Krum JM, et al. Activation of receptor-mediated angiogenesis and signaling pathways after VEGF administration in fetal rat CNS explants. J Cereb Blood Flow Metab. 2003; 23: 1420-9.

25. Zhu W, Mao Y, Zhao Y, et al. Transplantation of vascular endothelial growth factor-transfected neural stem cells into the rat brain provides neuroprotection after transient focal cerebral ischemia. Neurosurgery. 2005; 57: 325-33.

26. Marti HH. Erythropoietin and the hypoxic brain. J Exp Biol. 2004; 207: 3233-42.

27. Marti HH. Vascular endothelial growth factor. Adv Exp Med Biol. 2002; 513: 375-94.

28. Gerber HP, Malik AK, Solar GP, et al. VEGF regulates haematopoietic stem cell survival by an internal autocrine loop mechanism. Nature. 2002; 417: 954-8.

29. Marti HH and Risau W. Angiogenesis in ischemic disease. Thromb Haemost. 1999; 82(Suppl 1): 44-52.

30. Muller FJ, Snyder EY and Loring JF. Gene therapy: can neural stem cells deliver? Nat Rev Neurosci. 2006; 7: 75-84.

31. Young PP, Hofling AA and Sands MS. VEGF increases engraftment of bone marrow-derived endothelial progenitor cells (EPCs) into vasculature of newborn murine recipients. Proc Natl Acad Sci (USA). 2002; 99: 11951-6.

32. Smythe GM, Lai MC, Grounds MD, et al. Adeno-associated virus-mediated vascular endothelial growth factor gene therapy in skeletal muscle before transplantation promotes revascularization of regenerating muscle. Tissue Eng. 2002; 8: 879-91.

33. Palmer TD, Willhoite AR and Gage FH. Vascular niche for adult hippocampal neurogenesis. J Comp Neurol. 2000; 425: 479-94.

34. Shen Q, Goderie SK, Jin L, et al. Endothelial cells stimulate self-renewal and expand neurogenesis of neural stem cells. Science. 2004; 304: 1338-40. 